\title{
THE LITERATURE REVIEW OF TECHNOLOGY ADOPTION MODELS AND THEORIES FOR THE NOVELTY TECHNOLOGY
}

PC Lai

Help University, Malaysia

\begin{abstract}
This paper contributes to the existing literature by comprehensively reviewing the concepts, applications and development of technology adoption models and theories based on the literature review with the focus on potential application for the novelty technology of single platform Epayment. These included, but were not restricted to, the Theory of Diffusion of Innovations (DIT) (Rogers, 1995), the Theory of Reasonable Action (TRA) (Fishbein and Ajzen, 1975), Theory of Planned Behavior (TPB) (Ajzen, 1985, 1991), Decomposed Theory of Planned Behaviour, (Taylor and Todd, 1995), the Technology Acceptance Model (TAM) (Davis, Bogozzi and Warshaw, 1989, Technology Acceptance Model 2 (TAM2) Venkatesh and Davis (2000) and Technology Acceptance Model 3 (TAM3) Venkatesh and Bala (2008). These reviews will shed some light and potential applications for technology applications for future researchers to conceptualize, distinguish and comprehend the underlying technology models and theories that may affect the previous, current and future application of technology adoption.
\end{abstract}

Keywords: TAM, TRA, TBP, DIT, TTF, technology adoption, single platform E-payment

\section{INTRODUCTION}

Constant technological change simultaneously creates threats to established business models, while also offering opportunities for novel service offerings (Lai, 2006; 2007; 2010; 2016). Leading firms often seek to shape the evolution of technological applications to their own advantage (Lovelock, 2001; Lai, 2007). With the advanced and dynamic growth of technologies, how fast the consumers are accepting these technologies depends on a number of factors such as availability of technology, convenience, consumers' need, security etc. There have been a number of researchers addressing the consumers' adoption of new technologies (Meuter, Ostrom, Roundtree, and Bitner, 2000; Dapp, Stobbe, and Wruuck. 2012; Lai and Zainal, 2014,

Manuscript first received/Recebido em: 2017/03/17 Manuscript accepted/Aprovado em: 2017/04/17

Address for correspondence / Endereço para correspondência

PC Lai, Help University, Malaysia. E-mail: pcresearch8@ gmail.com

Published by/ Publicado por: TECSI FEA USP - 2016 All rights reserved 
2015; Lai, 2016). Therefore, this paper presents the literature review of the technology acceptance models and theories leading to the development of the novel technology single platform E-payment theoretical framework.

This paper analyzed the technology adoption models and theories leading to the theoretical framework for an integrated E-payment system known as the "single platform Epayment System" of the technology acceptance for Card, Internet and Mobile. These included, but were not restricted to, the Theory of Diffusion of Innovations (DIT) (Rogers, 1995) that started in 1960, the Theory of Task-technology fit (TTF) (Goodhue, and Thompson, 1995), the Theory of Reasonable Action (TRA) (Fishbein and Ajzen, 1975), Theory of Planned Behavior (TPB) (Ajzen, 1985, 1991), Decomposed Theory of Planned Behaviour, (Taylor and Todd, 1995), the Technology Acceptance Model (TAM) (Davis, Bogozzi and Warshaw, 1989), Final version of Technology Acceptance Model (TAM) Venkatesh and Davis (1996), Technology Acceptance Model 2 (TAM2) Venkatesh and Davis (2000), Unified Theory of Acceptance and Use of Technology (UTAUT), Venkatesh, Morris, Davis and Davis (2003) and Technology Acceptance Model 3 (TAM3) Venkatesh and Bala (2008). This review could shed some light and potential applications for technology applications for future researchers to conceptualize, distinguish and comprehend the underlying technology models and theories that might affect the previous, current and future application of technology adoption.

\section{TECHNOLOGY ADOPTION MODELS AND THEORIES}

Hoenig (1995) as well as Lai (2016) noted that the rate at which payment systems develop depends largely on a struggle between rapid technological change and natural barriers to new product or service acceptance. A number of theories have proposed to explain consumers' acceptance of new technologies and their intention to use. These included, but were not restricted to, the Theory of Diffusion of Innovations (DIT) (Rogers, 1995) that started in 1960, the Theory of Task-technology fit (TTF) (Goodhue, and Thompson, 1995), the Theory of Reasonable Action (TRA) (Fishbein and Ajzen, 1975), Theory of Planned Behavior (TPB) (Ajzen, 1985, 1991), Decomposed Theory of Planned Behaviour, (Taylor and Todd, 1995), the Technology Acceptance Model (TAM) (Davis, Bogozzi and Warshaw, 1989), Final version of Technology Acceptance Model (TAM) Venkatesh and Davis (1996), Technology Acceptance Model 2 (TAM2) Venkatesh and Davis (2000), Unified Theory of Acceptance and Use of Technology (UTAUT), Venkatesh, Morris, Davis and Davis (2003) and Technology Acceptance Model 3 (TAM3) Venkatesh and Bala (2008).

Rogers (1995) proposed that the theory of 'diffusion of innovation' was to establish the foundation for conducting research on innovation acceptance and adoption. Rogers synthesized research from over 508 diffusion studies and came out with the 'diffusion of innovation' theory for the adoption of innovations among individuals and organization. The theory explicates "the 
process by which an innovation is communicated through certain channels over time among the members of a social system" (Rogers, 1995, p. 5).

Basically, it's the process of the members of a social system communicated an innovation through certain channels over time known as diffusion. The Rogers' (1995) diffusion of innovation theory explained that the innovation and adoption happened after going through several stages including understanding, persuasion, decision, implementation, and confirmation that led to the development of Rogers (1995) S-shaped adoption curve of innovators, early adopters, early majority, late majority and laggards as shown in Figure 1.

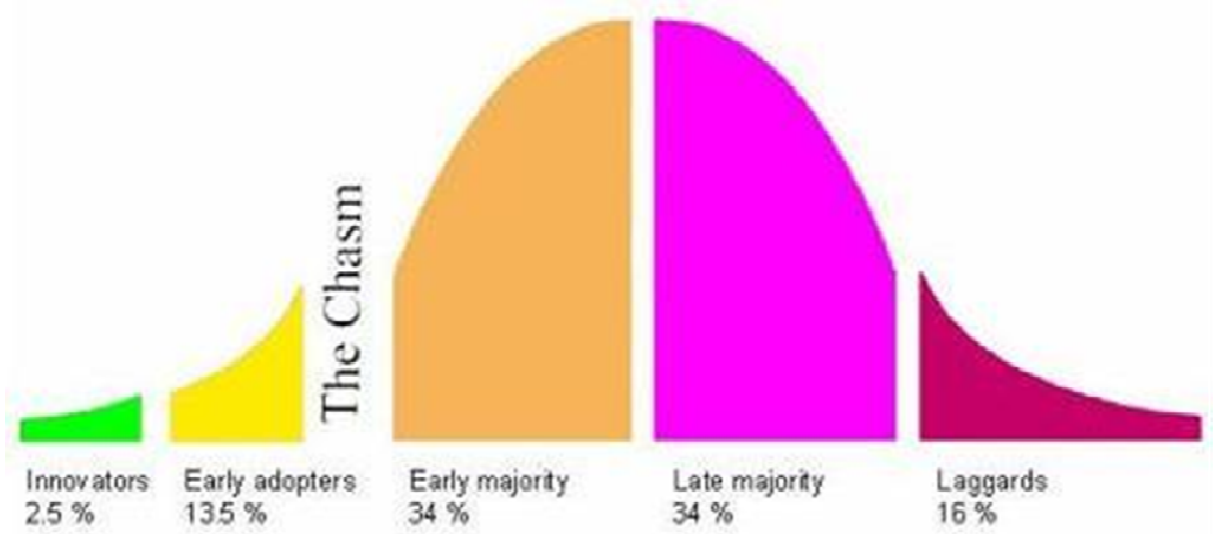

Figure 1. Innovation Adoption Curve (Roger, 1995)

Technology readiness (TR) refers to people's propensity to embrace and use of new technologies for accomplishing goals in home life and at work (Parasuraman and Colby, 2001). Based on individual's technology readiness score and the technology readiness, Parasuraman and Colby (2001) further classified technology consumers into five technology readiness segments of explorers, pioneers, skeptics, paranoids, and laggards. This is similar to Rogers (1995) S-shaped adoption curve of innovators, early adopters, early majority, late majority and laggards. The Diffusion of innovation or Technology readiness is vital for organization implementation success because it is market focus.

According to Goodhue et al. (1995), Task-technology Fit (TTF) emphasizes individual impact. Individual impact refers to improved efficiency, effectiveness, and/or higher quality. Goodhue et al. (1995) assumed that the good fit between task and technology is to increase the likelihood of utilization and also to increase the performance impact since the technology meets the task needs and wants of users more closely. As shown in Figure 2, this model is suitable for investigating the actual usage of the technology especially testing of new technology to get 
feedback. The task-technology fit is good for measuring the technology applications already release in the marketplace like in the google play store or apple store app (iTunes) etc.

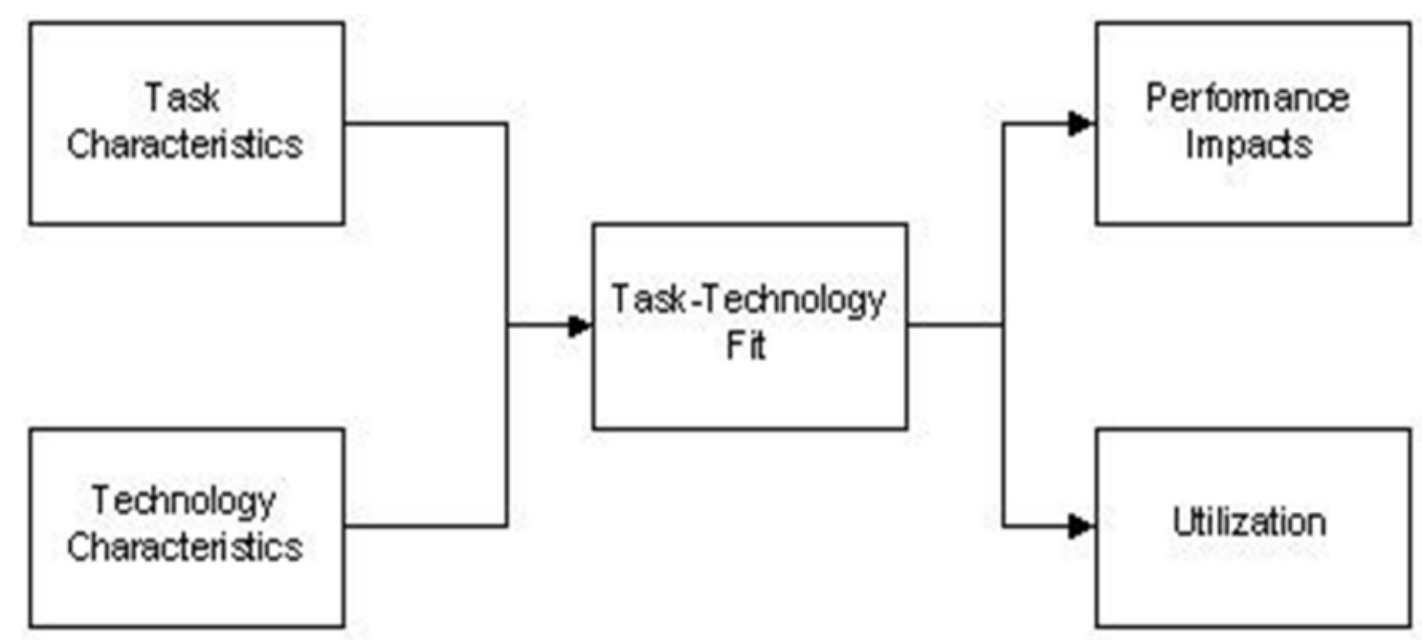

Figure 2. Task-technology fit (Goodhue and Thompson, 1995)

The Theory of Reasonable Action (Fishbein and Ajzen, 1975) is one of the most popular theories used and is about one factor that determines behavioural intention of the person's attitudes toward that behaviour as shown in Figure 3. Fishbien and Ajzen (1975) defined "attitude" as the individual's evaluation of an object and defined "belief" as a link between an object and some attribute, and defined "behaviour" as a result or intention. Attitudes are affective and based upon a set of beliefs about the object of behaviour (e.g: Credit card is convenient). A second factor is the person's subjective norms of what they perceive their immediate community's attitude to certain behaviour (e.g: my peers are using credit card and it's a status to have one). 


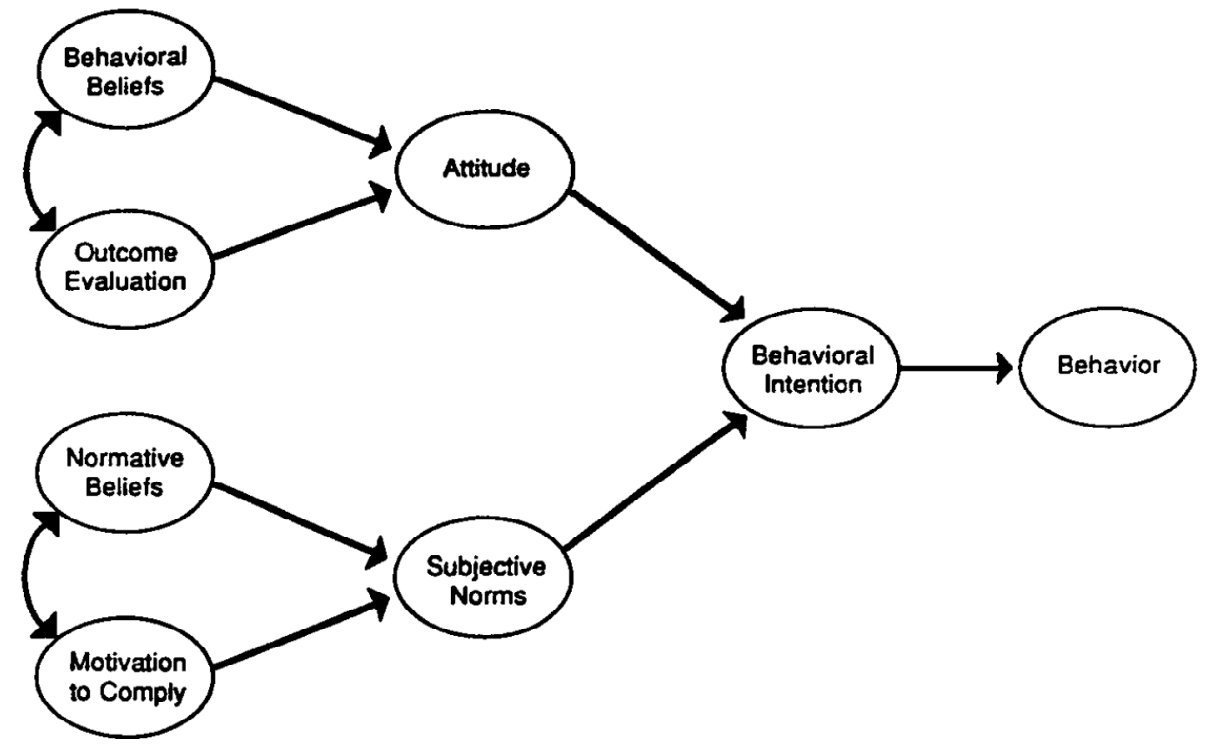

Figure 3. The Theory of Reasonable Action (Fishbein and Ajzen, 1975)

Ajzen (1991) developed Theory of Planned Behavior which is about one factor that determines behavioural intention of the person's attitudes toward that behaviour as shown in Figure 4. The first two factors are the same as Theory of Reasonable Action (Fishbein and Ajzen, 1975). The third factor that is known as the perceived control behaviour is the control which users perceive that may limit their behaviour (e.g: Can I apply for the credit card and what are the requirements?).

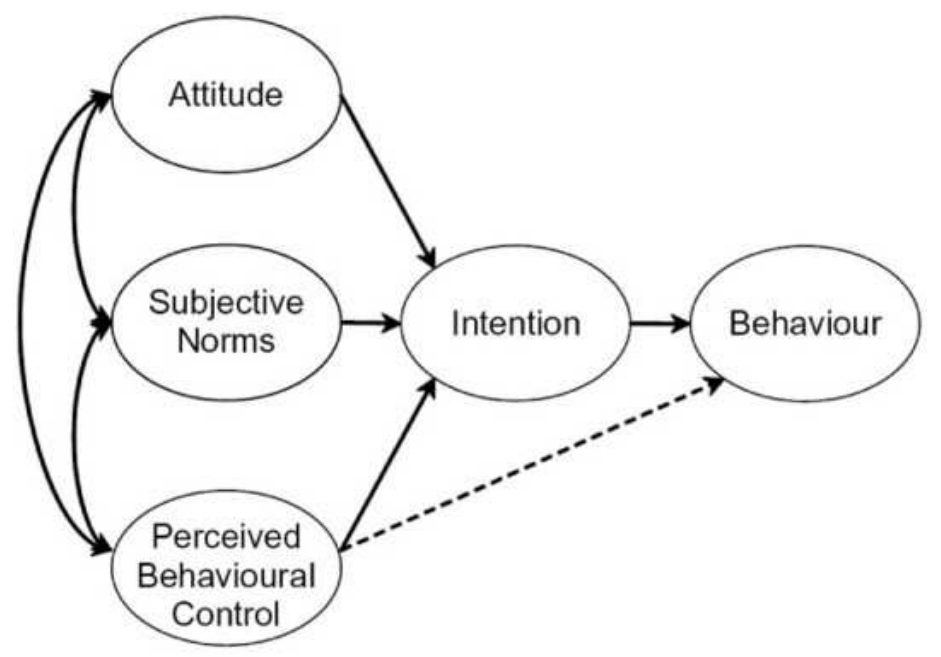

Figure 4. The Theory of Planned Behavior (Ajzen, 1991) 
Decomposed Theory of Planned Behaviour (Decomposed TPB) was introduced by Taylor and Todd (1995). The Decomposed TPB consists of three main factors influencing behavior intention and actual behavior adoption which are attitude, subjective norms and perceived behavior control. Shih and Fang (2004) examined the adoption of internet banking by means of the TPB as well as Decomposed TPB.

There has been a great deal of research on the Theory of Reasoned Action (Ajzen \& Fishbein, 1980; Sheppard, Hartwick, and Warshaw, 1988) Theory of Planned Behavior (Ajzen, 1991) and Decomposed Theory of Planned Behaviour, (Taylor and Todd, 1995) but mostly used for products already in the marketplace and included the view of society (Subjective norm).

Technology Acceptance Model (TAM) was introduced by Fred Davis in 1986 for his doctorate proposal as shown in Figure 5. An adaptation of Theory of Reasonable Action, TAM is specifically tailored for modeling users' acceptance of information systems or technologies.

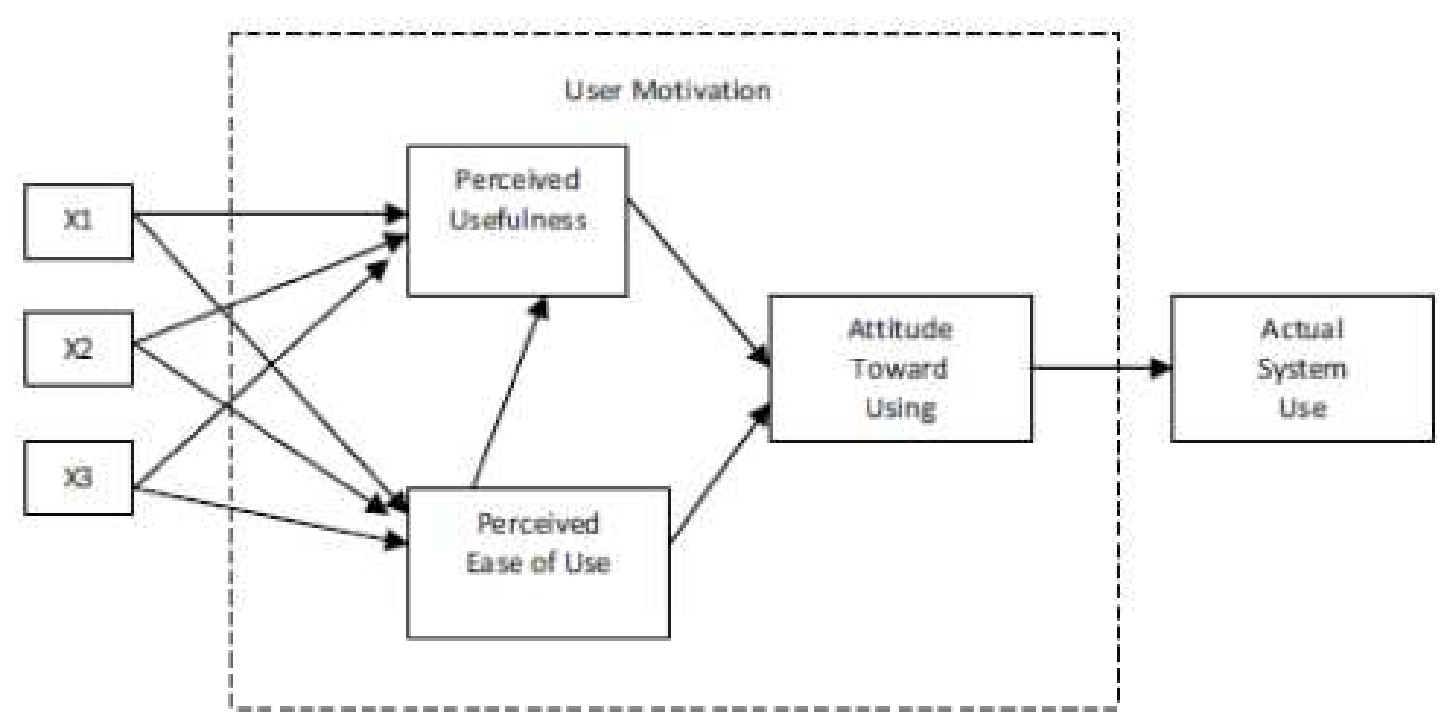

Figure 5. Original Technology Acceptance Model (Davis, 1986).

In 1989, Davis used TAM to explain computer usage behaviour as shown in Figure 6. The goal of Davis' (1989) TAM is to explain the general determinants of computer acceptance that lead to explaining users' behaviour across a broad range of end-user computing technologies and user populations. The basic TAM model included and tested two specific beliefs: Perceived Usefulness (PU) and Perceived Ease of Use (PEU). Perceived Usefulness is defined as the potential user's subjective likelihood that the use of a certain system (e.g: single platform Epayment System) will improve his/her action and Perceived Ease of Use refers to the degree to which the potential user expects the target system to be effortless (Davis, 1989). The belief of the person towards a system may be influenced by other factors referred to as external variables in TAM. 


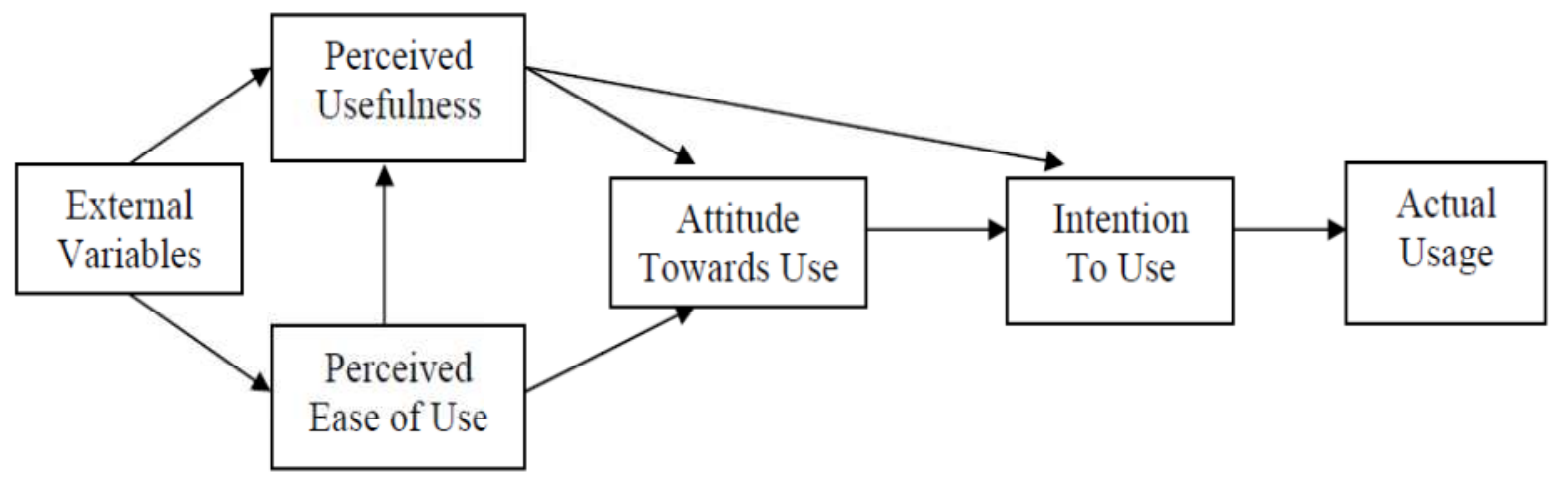

Figure 6. First modified version of Technology Acceptance Model (TAM) (Davis, Bogozzi and Warshaw, 1989).

The final version of Technology Acceptance Model was formed by Venkatesh and Davis (1996) as shown in Figure 7 after the main finding of both perceived usefulness and perceived ease of use were found to have a direct influence on behaviour intention, thus eliminating the need for the attitude construct.

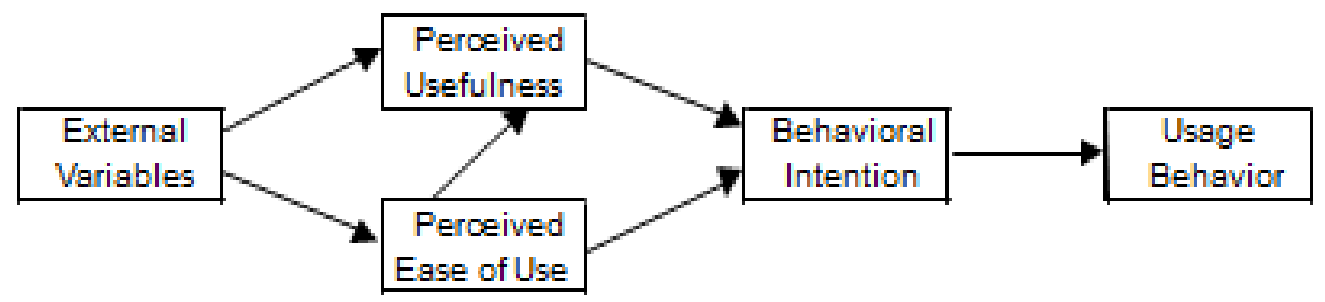

Figure 7. Final version of Technology Acceptance Model (TAM) (Venkatesh and Davis, 1996).

Venkatesh and Davis (2000) proposed the TAM 2 as shown in Figure 8. This study provided more detail explanations for the reasons users found a given system useful at three (3) points in time: pre-implementation, one month post-implementation and three month postimplementation. TAM2 theorizes that users' mental assessment of the match between important goals at work and the consequences of performing job tasks using the system serves as a basis for forming perceptions regarding the usefulness of the system (Venkatesh and Davis, 2000). The results revealed that TAM 2 performed well in both voluntary and mandatory environment. 


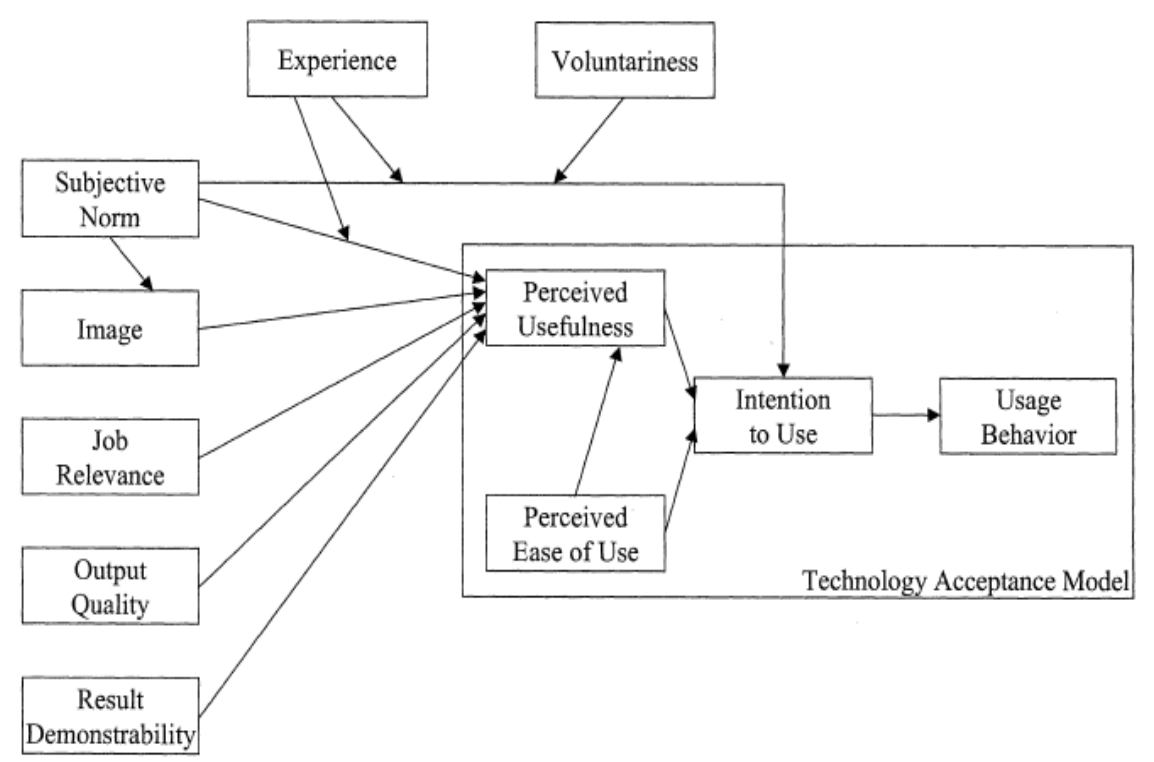

Figure 8. Technology Acceptance Model (TAM 2) (Venkatesh and Davis, 2000).

Venkatesh and Bala (2008) combined TAM2 (Venkatesh \& Davis, 2000) and the model of the determinants of perceived ease of use (Venkatesh, 2000), and developed an integrated model of technology acceptance known as TAM3 shown in Figure 9. The authors developed the TAM3 using the four different types including the individual differences, system characteristics, social influence, and facilitating conditions which are determinants of perceived usefulness and perceived ease of use. In TAM3 research model, the perceived ease of use to perceived usefulness, computer anxiety to perceived ease of use and perceived ease of use to behavioral intention were moderated by experiences. The TAM3 research model was tested in real-world settings of IT implementations. 


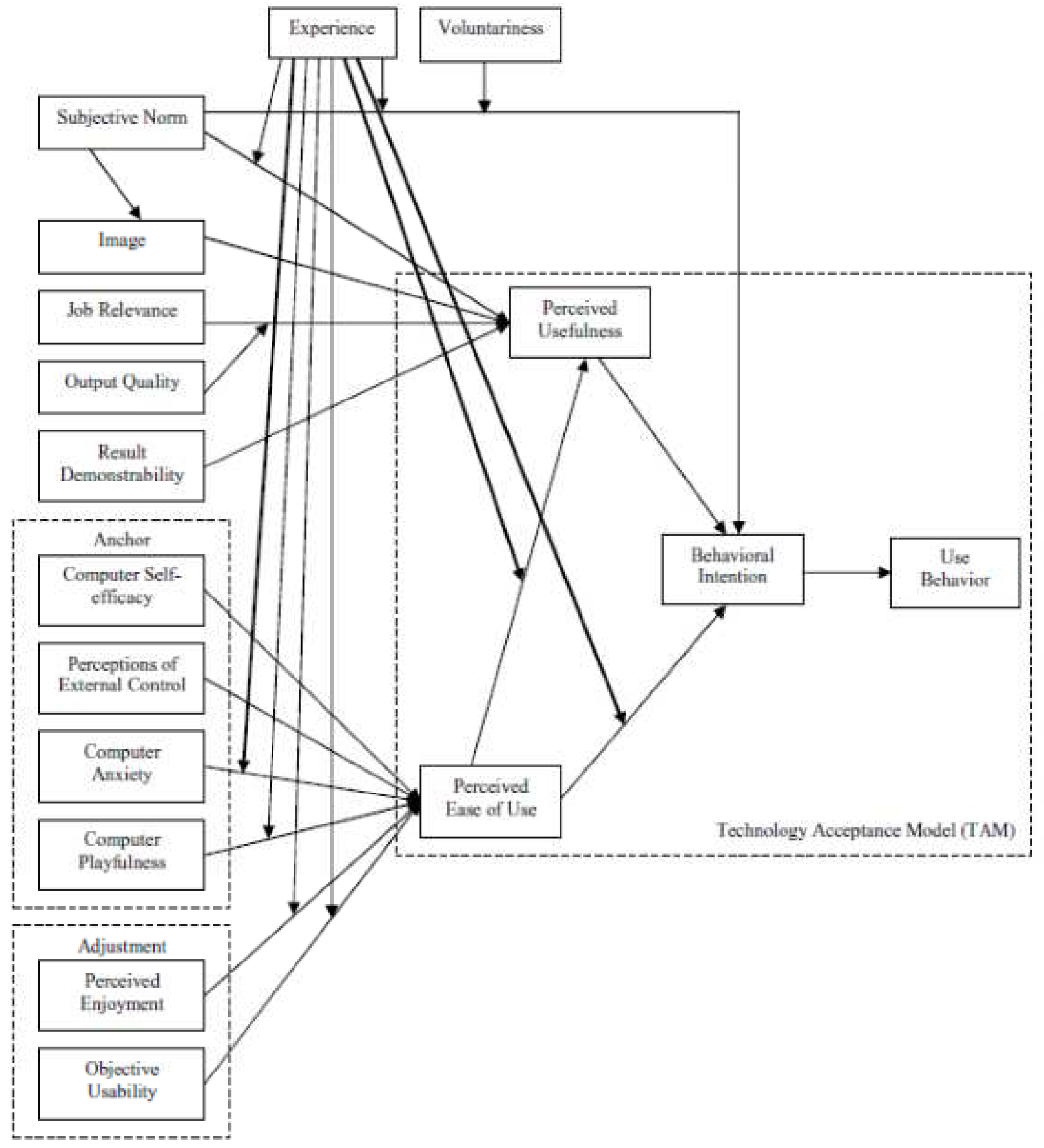

Figure 9. Technology Acceptance Model (TAM 3) (Venkatesh and Bala, 2008). 


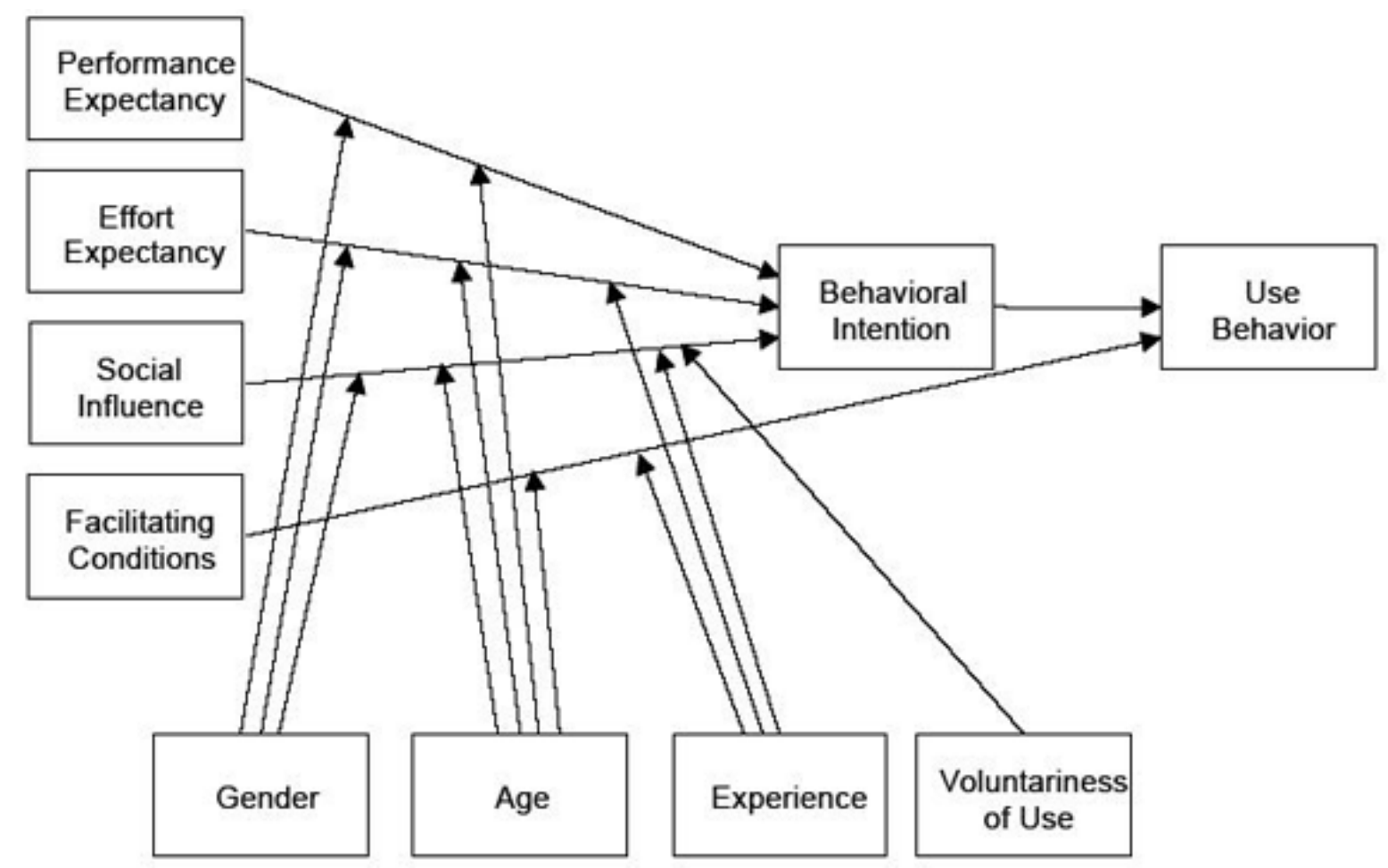

Figure 10. Unified Theory of Acceptance and Use of Technology (UTAUT) (Venkatesh, Morris, Davis and Davis, 2003).

Venkatesh, Morris, Davis and Davis (2003) studied from the previous models/theories and formed Unified Theory of Acceptance and Use of Technology (UTAUT) shown in Figure 10. The UTAUT has four predictors of users' behavioral intention and there are performance expectancy, effort expectancy, social influence and facilitating conditions. The five similar constructs including perceived usefulness, extrinsic motivation, job-fit, relative advantage and outcome expectations form the performance expectancy in the UTAUT model while effort expectancy captures the notions of perceived ease of use and complexity. As for the social context, Venkatesh et al. (2003) validation tests found that social influence was not significant in voluntary contexts.

\subsection{COMPARING THE MODELS}

The TAM, TRA, TPB, TAM2, TAM3 and UTAUT have been used over the years by various researchers to explain the adoption technology systems. This section will briefly discuss the comparisons of these theories and lead to why TAM is selected for the novel technology of single platform E-payment. 
These studies provide different context and methodology measuring different variables using different models in different settings. After reviewing all the technology adoption models, this paper will discuss the three most likely technology adoption models by comparing the Technology Acceptance Models (TAM), Theory of Reasoned Action (TRA) and Theory of Planned Behavior (TPB). In addition, this paper will discuss the extension TAM models TAM2, TAM3, UTAUT as well and then discuss the TAM as framework for the novel technology of single platform E-payment.

\subsection{COMPARING TECHNOLOGY ACCEPTANCE MODELS (TAM), THEORY OF REASONED ACTION (TRA) AND THEORY OF PHANNED BEHAVIOR (TPB)}

Davis, Bagozzi and Warshaw's (1989) study compared the Technology Acceptance Model (TAM) with Theory of Reasoned Action (TRA) and resulted in the convergence of TAM and TRA. This led to a model based on the three theoretical determinants which are the perceived usefulness, perceived ease of use and behaviour intention. The study found social norms (SN) as an important determinant of behavior intention to be weak. TAM does not include social norms ( $\mathrm{SN}$ ) as a determinant of behavior intention (BI), which is an important determinant, theorized by Theory of Reasoned Action TRA and Theory of Planned Behavior (TPB).

Mathieson (1991) and Yi, Jackson, Park, and Probst (2006) argued that human and social factors could play a role in the adoption of technology using TPB model. Therefore, the TAM could be extended with constructs from the TPB to incorporate the social factors that could explain technology adoption. Nevertheless, the TPB in Chau and Hu (2002) noted that social norm and behavior intention to use finding was negative and did not support that social norm would influence behavior intention. Shih and Fang (2004) also examined the adoption of internet banking by means of the TPB as well as Decomposed TPB and found that it was in line with the findings of Venkatesh and Davis (2000) that subjective norm was likely to have a significant influence on behavioural intention to use in a mandatory environment, whilst the effect could be insignificant in a voluntary environment. Since, this study is voluntary; therefore the Shih and Fang (2004) study will not apply in the novel technology of single platform E-payment System.

Davis, Bagozzi and Warshaw (1989) explained that social norms scales had a very poor psychometric standpoint, and might not exert any influence on consumers' behavior intention, especially when the information system application like single platform E-payment System was fairly personal while individual usage was voluntary. TAM was also specifically designed to address the factors of users' system technology acceptance (Chau and $\mathrm{Hu}$ 2002). Thus, the comparisons of the study confirmed that Technology Acceptance Model was easy to apply across different research settings. Han (2003) as well as Lai and Zainal (2014; 2015) noted that using TAM capability was favorable compared with TRA and TPB. 

UTAUT

TAM2, an extension of the TAM was developed by Venkatesh and Davis (2000) due to the limitations of the TAM in terms of explanatory power $\left(\mathrm{R}^{2}\right)$. The aspiration for the TAM2 was to keep the original TAM constructs intact and "include additional key determinants of TAM's perceived usefulness and usage intention constructs, and to understand how the effect of these determinants changed with increasing users' experience over time with the target system" (Venkatesh \& Davis, 2000, p.187). Because TAM2 only focused on the determinants of TAM's perceived usefulness and usage intention constructs, TAM3 by Venkatesh and Bala (2008) added the determinants of TAM's perceived ease of use and usage intention constructs for robustness. Therefore, TAM3 presented a complete nomological network of the determinants of users' Information Technology System adoption (Venkatesh and Bala, 2008).

Venkatesh et al. (2003) incorporated four key determinants in the UTAUT model and there were performance expectancy, effort expectancy, social influence and facilitation conditions as well as four key moderators like gender, age, voluntariness and experience. According to Bagozzi (2007), UTAUT might be a powerful model due to its parsimonious structure and higher explanatory power $\left(\mathrm{R}^{2}\right)$ but the model did not examine direct effects which might reveal new relationships as well as important factors from the study which were left out by subsuming under the existing predictors only. TAM2 and TAM3 also did not measure and examine direct effects which might reveal new relationships as well as important factors from the study.

Technology Acceptance Model (TAM2) by Venkatesh and Davis (2000), TAM3 by Venkatesh and Bala (2008) and UTAUT by Venkatesh, Morris, Davis and Davis (2003) were not selected since the situation was for products to be implemented in the marketplace and taken into consideration of subjective norm that included society not required for this study involving the novelty technology of single platform E-payment System. Davis, Bagozzi and Warshaw (1989) explained that social norms scales had a very poor psychometric standpoint, and might not exert any influence on consumers' behavior intention, especially when information system application like single platform E-payment System was fairly personal while individual usage was voluntary. UTAUT is an extension from TAM2 and TAM3 is an extension of TAM2 that includes social influence, therefore they will not be used in this study based on social norm. TAM2, TAM3 and UTAUT use moderators but the present study only focuses on the factors and consumers' intention to use single platform E-payment System. Furthermore, TAM2, TAM3 and UTAUT did not include direct relations studies. Therefore, TAM2, TAM3 and UTAUT were not favorable to study the novelty technology of single platform E-payment System. 


\subsection{EXTENSION FROM TAM FOR THE NOVEL TECHNOLOGY OF SINGLE PLATFORM E-PAYMENT SYSTEM}

A novel technology discussed here will be the single platform E-payment System. According to (Lai and Zainal, 2015), there is a lack of empirical investigations combining the factors of the three E-payments (Card, Internet and Mobile) in one study which encourages the researcher to study the single platform E-Payment system since previous researches only focused on the three systems separately (Card, Internet, Mobile). As the future integrated E-payment instruments, single platform E-payment system is a novel system as previous researches only focused on the three systems separately and individually (Card, Internet, Mobile) Lai, (2016).

TAM model developed by Davis is the most used framework in predicting information technology adoption (Paul, John and Pierre, 2003). Lee and Jun (2007) argued that TAM should be able to analyze factors affecting adoption intentions beyond perceptions of convenience and usefulness. Though TAM had received much support (Yang, 2005), it focused on the effects of perceptions of the technology's usefulness and convenience on adoption intentions (Luarn and Lin, 2005; Lai and Zainal, 2015). Thus, it is favorable for the use of determining the novelty technology like the single platform E-payment System.

In fact, TAM has become so popular that it has been cited in most of the research that deals with users' acceptance of technology (Lee, Kozar and Larsen, 2013). TAM attempts to help researchers and practitioners to distinguish why a particular technology or system may be acceptable or unacceptable and take up suitable measures by explanation besides providing prediction. Even though TAM has been tested widely with different samples in different situations and proved to be valid and reliable model explaining information system acceptance and use (Mathieson, 1991; Davis and Venkatesh, 1996,), many extensions to the TAM have been proposed and tested (e.g. Venkatesh and Davis, 2000; Venkatesh, Speier and Morris 2002; Henderson and Divett, 2003; Lu, Yu, Liu, and Yao, 2003; Lai and Zainal, 2014; 2015; Lai, 2016).

Davis (1986) mentioned that behavior intention to use was being mediated by attitude. Nevertheless, attitude was excluded as its mediator in Venkatesh and Davis (2000) TAM2 and theorized a direct relationship between the constructs and intention to use. TAM initially included attitude, but this was later dropped due to its weak role as a mediator between the constructs and intention to use (Mun, Joyce, Jae \& Janice, 2006). Thus, in this paper the study has adapted the Venkatesh and Davis' (1996) version of TAM to measure consumers' behavior intention to use instead of Davis' (1986) version by omitting the attitude towards use and actual usage for the novel technology of single platform E-payment (Lai and Zainal, 2015). In addition, the study will extend the 1996 version of Technology Acceptance Model by including security factors and use the mediator with the direct and indirect relationship of the factors and consumers' intention to use the single platform E-payment System (Lai, 2016). Therefore, in figure 11 showed the Stimulus Theoretical Framework for the novelty technology of the single platform E-payment System. According to Lai (2016), the design and security are the stimulus that represent the system and features capabilities while, the perceived ease of use and perceived 
usefulness are the organism that represents the motivation to use the system that leads to consumers' respond to use the system. The Stimulus Theoretical Framework provides the structure for the research hypothesis. Thus, the figure 11 also showed the "Design and Security Stimulus Research Theoretical Hypothesis" (Lai, 2016).

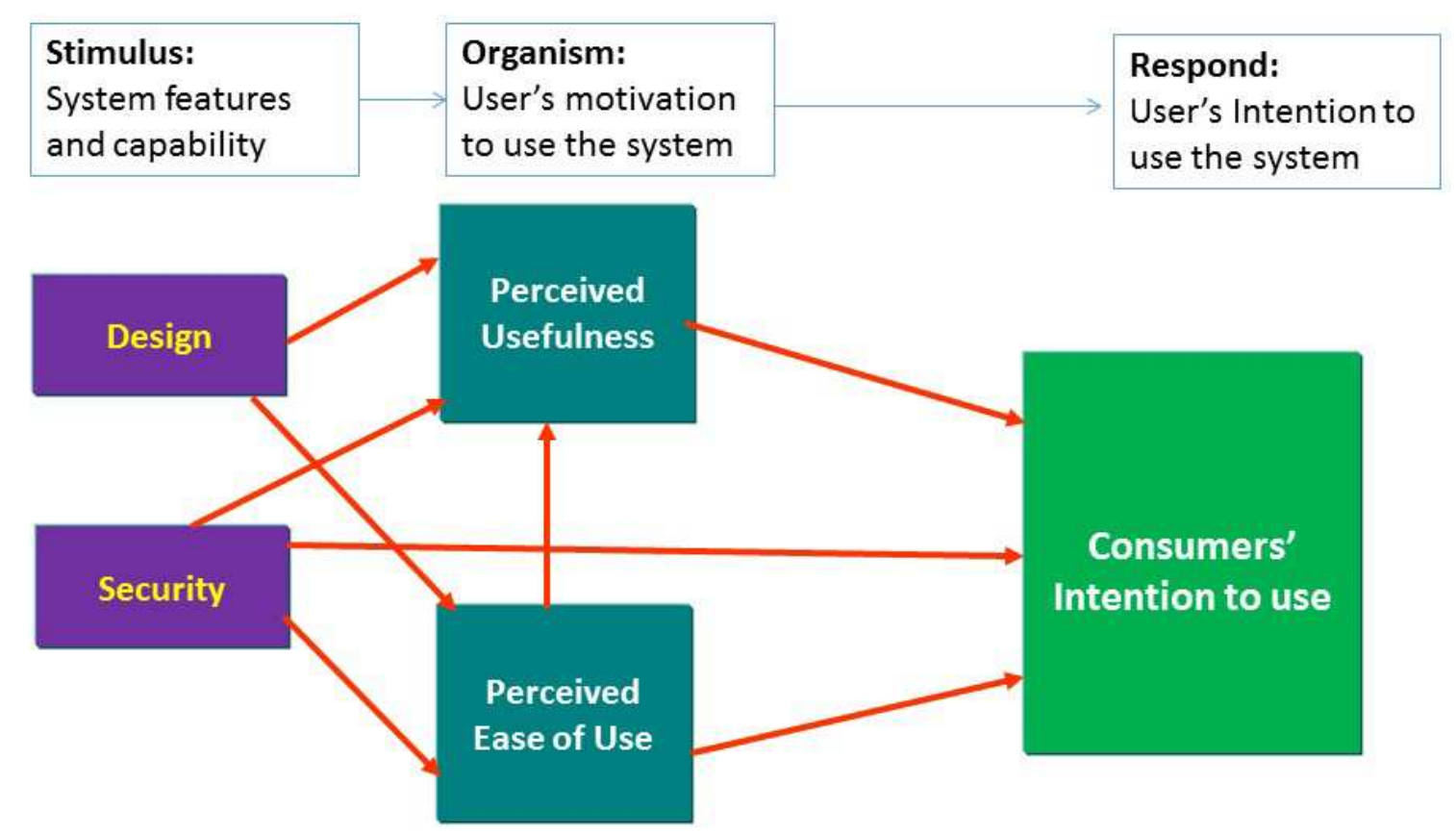

Figure 11. Stimulus Theoretical Framework (Design and Security Stimulus Research Theoretical Hypothesis) (Lai, 2016).

\section{CONCLUSION}

The above discussion, concepts, applications and development of technology adoption models and theories based on the literature review encompass different views and interpretations. The literature reviews share the difference of technology adoption models and theories with different theoretical insights, research problems, variables, and measurements. The development of the new theoretical research framework will depend on a number of factors but not limited to the following: the research problems and objectives, gap analysis, the target market (users or developers, etc), the organizations' goals and the understanding of technology adoption models and theories based on the available materials and others. Such understanding is vital to enable the interested parties (e,g: students, academics, researchers, government, organizations) to relate with both the theory and practical aspects of the technology adoption models and theories. These reviews will shed some light and potential applications for technology applications for future researchers to conceptualize, distinguish and comprehend the underlying technology models and theories that may affect the previous, current and future application of technology adoption. 


\section{REFERENCES}

Ajzen, I. (1991). The Theory of Planned Behavior. Organization Behavior and Human Decision Processes, Academic Press, Inc. 179-211.

Bagozzi, R.P. (2007) The Legacy of the Technology Acceptance Model and a Proposal for a Paradigm Shift. Journal of the Association for Information Systems, 8, 244-254.

Chau, P. Y. K., and Hu, P., J. (2002). Examining a model of information technology acceptance by individual professionals: An exploratory study. Journal of Management Information Systems, 18 (4), 191-229.

Davis, F.D. (1986). A technology acceptance model for empirically testing new end-user information systems: Theory and results. Massachusetts, United States: Sloan School of Management, Massachusetts Institute of Technology.

Davis, F. D. (1989). Perceived usefulness, perceived ease of use, and user acceptance of information technology. MIS Quarterly, 13(3), 319-340.

Davis, F. D., Bogozzi, R., P., \& Warshaw, P., R. (1989). User acceptance of computer technology: A comparison of two theoretical models. Management Science, 35, 982-1003.

Davis, F. D. (1993). User acceptance of information technology: system characteristics, user perceptions and behavioral impacts. International Journal of Man-Machine Studies. 38, (3), 475487

Davis, F. D., and V. Venkatesh. (1996). A critical assessment of potential measurement biases in the technology acceptance model: Three experiments Internet. J. Human-Comput. Stud. 45 1945 .

Dapp. T, Stobbe, A., and Wruuck P. 2012. The future of (mobile) payments - New (online) players competing with banks, Deutsche Bank Research, 20th December 2012, pp.1-31.

Dewan \& Chen. (2005). Mobile payment adoption in the US: A cross-industry, cross platform solution. Journal of Information Privacy and Security. 1 (2), $4-25$.

Fishbein, M., \& Ajzen, I. (1975). Belief, attitude, intention, and behavior: An introduction to theory and research. Reading, Mass; Don Mills, Ontario: Addison-Wesley Pub. Co.

Goodhue, D. L., \& Thompson, R. L. (1995). Task technology fit and individual performance. MIS Quarterly, 19, 213-236.

Han, S. (2003). Individual adoption of information systems in organisations: a literature review of technology acceptance model TUCS Technical Report 540; TUCS. 
Henderson, R. \& Divett., M., J. (2003). Perceived usefulness, ease of use and electronic supermarket use. International Journal of Human-Computer Studies, 59, 383-395.

Lai P. C (2006). The significant of E-business and knowledge-based Customer Relationship in the E-market Place Environment. INTI Journal, 2 (1) 552-559.

Lai, P. C. (2007). The Chip Technology Management Implication in the Era of Globalization: Malaysian Consumers' Perspective, Asia Pacific Business Review, 3(1), 91-96

Lai P. C. (2010). E-business and E-banking. Japan Society for Software Science and Technology, Itech research group.

Lai, P. C. (2014) "Factors influencing consumers' intention to use a single platform E-payment System." UNITEN.

Lai, P. C. (2013) "Cashless, Cardless, Contactless and Convenience of MySIM"M." GlobalCLAS Technology..

Lai P. C. \& Ahmad, Z. A. (2014). Perceived Enjoyment of Malaysian consumers' intention to use a single platform E-payment. Paper presented at International Conference on Liberal Arts \& Social Sciences., 25th - 29th April, 2014, Hanoi, Vietnam

Lai P. C. \& Zainal A. A., (2015). Consumers' Intention to Use a Single Platform E-Payment System: A Study among Malaysian Internet and Mobile Banking Users. Journal of Internet Banking and Commerce. (20) (1) 1-13

Lai P. C. \& Zainal A.A, (2015). Perceived Risk as an Extension to TAM Model: Consumers' Intention To Use A Single Platform E-Payment. Australia Journal Basic and Applied Science, 9(2): 323-330.

Lai, P. C. (2016) Design and Security impact on consumers' intention to use single platform Epayment, Interdisciplinary Information Sciences, 22 (1), 111-122

Lee, T.M., \& Jun, J.K. (2007). The role of contextual marketing offer in Mobile commerce acceptance: comparison between Mobile Commerce users and nonusers. International Journal of Mobile Communications, 5(3), 339-356.

Lee, Y., Kozar, K. A., \& Larsen, K. R. T. (2003). The technology acceptance model; past, present and future. Communication of AIS, 12 (50), 752-780.

Luarn, P., \& Lin, H., H. (2005). "Toward an understanding of the behavioral intention to use mobile banking." Computers I Human Behavior, 21, 873-891.

Lu, J., Yu, C. S., Liu, C., \& Yao, J. (2003). Technology acceptance model for wireless internet. Journal of Internet Research, 13(2), 206-222.

Lovelock, C. (2001). Services Marketing, People, Technology, Strategy, Prentice Hall, New Jersey. 
Mathieson, K. (1991). Predicting user intentions: Comparing the technology acceptance model with the theory of planned behavior. Information Systems Research, 2(3), 173-191.

Meuter, M. L., Ostrom, A. L., Roundtree, R. I., \& Bitner, M. J. (2000). Self-service technologies: Understanding customer satisfaction with technology-based service encounters. Journal of Marketing, 64(3), 50-65.

Mun Y. Yi, Joyce D. J., Jae S. P. \& Janice C. P. (2006). Understanding information technology acceptance by individual professionals: Toward an integrative view. Information \& Management, 43, 350-363

Parasuraman, A., \& Colby L. C. (2001). Techno-Ready Marketing, The Free Press.

Paul L., John I., \& Pierre, C. (2003). Why do people use information technology? A critical review of the technology acceptance model. Information \& Management, 40, 191-204.

Rogers, E.M. (1995). Diffusion of Innovations. 4th ed., New York: The Free Press

Sheppard, B. H., Hartwick, J., Warshaw. P. R., (1998) The Theory of Reasoned Action: A MetaAnalysis of Past Research with Recommendations for Modifications and Future Research. The Journal of Consumer Research, 15, (3) 325-343

Shih, Y.Y. \& Fang, K. (2004). The use of a Decomposed Theory of Planned Behavior to study Internet banking in Taiwan. Internet Research, 14 (3), 213-223.

Taylor, S. and Todd, P. A. (1995). Understanding Information Technology Usage: A Test of Competing Models. Information Systems Research, 6, 144-176.

Venkatesh, V., \& Davis, F. D. (1996). A model of the antecedents of perceived ease of use: Development and test. Decision Sciences, 27(3), 451-481.

Venkatesh,V. (2000). Determinants of perceived ease of use: integrating control, intrinsic motivation, and emotion into the technology acceptance model. Information Systems Research, 11(4), 342-365.

Venkatesh, V., \& Davis, F. D. (2000). A Theoretical Extension of the Technology Acceptance Model: Four Longitudinal Field Studies. Management Science, 46 (2), 186-204.

Venkatesh, V., and Morris, M. G. (2000). Why Don't Men Ever Stop to Ask For Directions? Gender, Social Influence, and Their Role in Technology Acceptance and Usage Behavior. MIS Quarterly (24:1), 115-139.

Venkatesh, V., Morris, M.G., Davis, F.D., \& Davis, G.B. (2003). User Acceptance of Information Technology: Toward a Unified View. MIS Quarterly, 27, 425-478.

Venkatesh, V. and Bala, H. (2008). Technology Acceptance Model 3 and a Research Agenda on Interventions. Decision Science, 39 (2), 273-312. 
Yang, K.C.C. (2005). Exploring factors affecting the adoption of mobile commerce in Singapore. Telematics and Informatics. 22, 257-277

Yi, M.Y., Jackson, J.D., Park, J.S. \& Probst, J.C. (2006). Understanding information technology acceptance by individual professionals: Toward an integrative view. Information \& Management, 43 (3), 350-363. 